\title{
Prevalence of hyperlipoproteinaemia in apparently healthy men
}

\author{
A. R. Lorimer, F. C. Cox, D. A. Greaves, J. S. Jubb, V. M. Hawthorne, H. G. Morgan, and \\ T. D. V. Lawrie \\ From University Departments of Medical Cardiology and Pathological Biochemistry, Royal Infirmary, and \\ University Department of Epidemiology and Preventive Medicine, Ruchill Hospital, Glasgow
}

Lipoprotein typing was carried out on 4385 apparently healthy male subjects at work in the Glasgow conurbation of the West of Scotland. Subjects were fasting and the investigations undertaken were cholesterol, triglyceride, lipoprotein paper electrophoresis, and preparative ultracentrifugation when necessary. 29.5 per cent of subjects were normal in terms of history, weight, blood pressure, electrocardiogram, and all smoked less than 5 cigarettes daily.

The overall prevalence of hyperlipoproteinaemia was I5.3 per cent and consisted of I2 per cent type IV and 3.3 per cent type II hyperlipoproteinaemia. Type II a abnormality occurred more frequently than type IIb.

There was a significantly higher prevalence $(I 7.6 \%, P<0.0 I)$ of type IV abnormality in the obese group.

In normal subjects the prevalence of type II abnormality was $3 \cdot I$ per cent, whereas that of type IV hyperlipoproteinaemia was 7 per cent.

In 1971 there were 17,656 deaths from ischaemic heart disease in Scotland. This accounted for 28.6 per cent of all deaths, $I$ in 3 male and $I$ in 4 female deaths in the country (Registrar General, 1972).

Epidemiological studies have indicated that hyperlipidaemia as shown by raised cholesterol or raised triglyceride, either singly or in combination, hypertension, and heavy cigarette smoking are among the major risk factors in the development of coronary heart disease (Blackburn, 1970; Carlson and Böttiger, 1972; Kannel et al., 1964). Advances in the study of hyperlipidaemia have led to the concept of the hyperlipoproteinaemias and to the development of lipoprotein typing systems, such as described by Fredrickson, Levy, and Lees (1967). There is, however, as yet little knowledge of the frequency with which lipoprotein abnormalities occur in the population in this country.

This study was, therefore, undertaken to investigate the prevalence of lipoprotein abnormalities in apparently healthy male subjects at work in the Glasgow conurbation of the West of Scotland, an area where there is a high incidence of coronary heart disease.

Received I6 August 1973. 
questionnaire containing standardized questions on history of chest pain (Rose and Blackburn, r968a), smoking habits, and bronchitis (M.R.C., I965). At the screening unit, the questionnaire was individually checked. Subsequently the procedure was as described by Hawthorne, Gillis, and MacLean (1972), with height, weight, blood pressure (Rose and Blackburn, I968b), a 6-lead electrocardiogram (3 standard and 3 unipolar limb leads), and chest radiograph being recorded.

Venous blood, Io $\mathrm{ml}$, was withdrawn from subjects who had been asked to fast for at least 9 hours before sampling. Plasma was separated and, when necessary, stored at $4^{\circ} \mathrm{C}$. Plasma total cholesterol and triglycerides were measured by autoanalyser techniques (Annan and Isherwood, I969; Kessler and Lederer, 1966). ${ }^{1}$ Plasma lipoprotein electrophoresis was carried out on each sample using albuminated barbitone buffer (Lees and Hatch, 1963). The age related upper normal limits used for cholesterol and triglyceride were those suggested by Fredrickson et al. (1967). Subjects who had probable postprandial hypertriglyceridaemia on the basis of chylomicrons detected on the electrophoretogram were reinstructed about the need for fasting, and sampling was repeated. Subjects with increases in both cholesterol and triglyceride were recalled in the fasting state, and a $35 \mathrm{ml}$ venous blood sample was obtained. The cholesterol content of each of the major lipoprotein fractions was determined following ultracentrifugation at I I4,000 for I6 hours (Fredrickson et al., 1967) and heparin and manganese precipitation of all lipoproteins other than high density lipoprotein (Burstein, Scholnick, and Morfin, 1970). Electrophoresis of the ultracentrifuged fractions at $\mathrm{D}<\mathrm{I} \cdot 006$ and at $\mathrm{D}>\mathrm{I} \cdot 006$ was also done. Following these investigations, the results were classified as follows.

I) Normal lipoproteins on the basis of normal total cholesterol and triglyceride and normal electrophoretogram.

2) Type IIa hyperlipoproteinaemia, as defined by a raised total plasma cholesterol, a normal total triglyceride, and a pronounced beta band on the electrophoretogram. Type IIb hyperlipoproteinaemia (Beaumont et al., 1970) as defined by a raised low density lipoprotein cholesterol and a raised total triglyceride value.

3) Type IV hyperlipoproteinaemia, as defined by a raised triglyceride, a normal total cholesterol, and a distinct pre-beta band on the electrophoretogram.

Types I, III, and V hyperlipoproteinaemia were not encountered in this study.

\section{Normal and abnormal participants}

The total population examined (4477) was divided into two subgroups designated 'normal' and 'abnormal'. The abnormal group contained subjects with any of the following conditions which were present in the proportion shown in Table 2.

${ }^{1}$ Laboratory techniques standardized with lipid standardization laboratory, Centre for Disease Control, Atlanta, Georgia, U.S.A.
TABLE 2 Health survey in West of Scotland men

\begin{tabular}{lc} 
Classification & Percentage \\
\hline Normal & $29 \cdot 5$ \\
Cigarette smoking & $59 \cdot 0$ \\
Obese & $28 \cdot 0$ \\
Hypertension & $7 \cdot 4$ \\
Abnormal electrocardiogram & 4.9 \\
Possible angina & $5 \cdot 0$
\end{tabular}

The following definitions were used: Cigarette smoking -5 or more cigarettes daily. Obesity - more than 10 per cent above predicted ideal weight. Hypertension - systolic blood pressure of more than $170 \mathrm{mmHg}$ and/or diastolic blood pressure of more than $100 \mathrm{mmHg}$ at time of study. Electrocardiographic abnormalities were those summarized as categories I and II in the Minnesota code. (Minnesota code $I$ : major $\mathrm{Q}$ wave or left bundle-branch block, groups $I \cdot I$ or $I \cdot 2$ or $7 \cdot I$. Minnesota code $I I$ : Minor $\mathrm{Q}$ wave, group $\mathrm{I} \cdot 3$, or $\mathrm{ST}$ depression groups, 4.1 or 4.2 or 4.3 , or $T$ wave abnormality, groups 5.1 or 5.2 or 5.3 .) A history of possible angina was obtained from the questionnaire.

Of the total group, 29.5 per cent were defined as normal using the above criteria.

\section{Data analysis}

Variables such as mean and standard deviations were calculated by conventional methods. Student's ' $t$ ' test or $\chi^{2}$ analysis was used as appropriate for calculation of levels of significance.

\section{Results}

Results for fasting cholesterol and triglyceride values were available from 4385 subjects (I 296 normal and 3089 having one or more abnormality as previously defined). Three subjects above 60 years of age were not included in the analysis. Obesity was the sole abnormality in 539 subjects There were 255 non-obese and non-cigarette smoking subjects who were found to have one or more of the other abnormalities defined above. There were 89 subjects from the 4474 who attended, in whom, for technical reasons, results were not obtained.

Cholesterol and triglyceride values for these subgroups are shown in Table 3. There is no significant difference in cholesterol values between the groups. Values tend to be lower in subjects less than 39 years but little change occurs thereafter. Triglyceride levels are significantly higher at all age groups in the obese group. There is, in general, no tendency for triglyceride values to increase with age. Normal levels appeared to decrease in the over 40 age groups. When subjects are considered who have an abnormality other than obesity or cigarette 
TABLE 3 Plasma total cholesterol and triglyceride values $(\mathrm{mg} / \mathrm{roO} \mathrm{ml})$ in normal subjects, those with an abnormality other than smoking or obesity, and those who are obese but otherwise normal (mean $\pm S D$ are shown)

\begin{tabular}{|c|c|c|c|c|c|c|c|c|c|}
\hline \multirow[t]{2}{*}{$\begin{array}{c}\text { Age } \\
(y r)\end{array}$} & \multicolumn{3}{|c|}{ Normal } & \multicolumn{3}{|c|}{$\begin{array}{l}\text { Abnormality other than smoking or } \\
\text { obesity }\end{array}$} & \multicolumn{3}{|c|}{ Obesity as sole abnormality } \\
\hline & No. & Chol. & $T G L$ & No. & Chol. & $T G L$ & No. & Chol. & $T G L$ \\
\hline$<39$ & 238 & $216 \pm 39$ & $102 \pm 76$ & 32 & $226 \pm 39$ & $117 \pm 73$ & 82 & $218 \pm 32$ & $135 \pm 119^{\star}$ \\
\hline $40-44$ & 365 & $227 \pm 38$ & $112 \pm 68$ & 49 & $237 \pm 52$ & $116 \pm 84$ & 119 & $226 \pm 4 I$ & $157 \pm 128^{\star}$ \\
\hline $45-49$ & 282 & $233 \pm 39$ & $110 \pm 53$ & 54 & $233 \pm 40$ & $118 \pm 6 I$ & 132 & $237 \pm 40$ & $132 \pm 66^{\star}$ \\
\hline $50-54$ & 249 & $234 \pm 38$ & $105 \pm 48$ & 71 & $241 \pm 45$ & $127 \pm 68$ & II4 & $225 \pm 37$ & $131 \pm 139^{\star}$ \\
\hline $55-59$ & 162 & $232 \pm 38$ & $104 \pm 44$ & 49 & $242 \pm 42$ & I $14 \pm 48$ & 92 & $229 \pm 38$ & $136 \pm 72^{\star}$ \\
\hline
\end{tabular}

$\star \mathbf{P}<0.01$ when compared to normal.

TABLE 4 Prevalence of types of hyperlipoproteinaemia in total population studied

\begin{tabular}{rrrrcc}
\hline Age (yr) & No. & $a{ }^{2}$ Type II & $b$ & Type IV & $\begin{array}{l}\text { Per cent } \\
\text { abnormal }\end{array}$ \\
\hline$<39$ & 654 & 30 & $\mathrm{r}$ & 93 & $19 \cdot 0$ \\
$40-44$ & 1057 & 38 & 4 & 160 & $19 \cdot 1$ \\
$45-49$ & 1034 & 43 & 4 & 142 & $18 \cdot 2$ \\
$50-54$ & 939 & 17 & 0 & 74 & $9 \cdot 6$ \\
$55-59$ & 701 & 13 & 1 & 52 & $9 \cdot 4$ \\
\hline
\end{tabular}

smoking, triglyceride levels are intermediate between those of the normal and obese groups.

Data in Table 4 indicate that type IV hyperlipoproteinaemia occurs more frequently than type II abnormality. It has an overall prevalence of $12 \cdot 0$ per cent compared to the 3.3 per cent found for type II hyperlipoproteinaemia. In type II hyperlipoproteinaemia, it was found that type IIa occurred more frequently than type IIb. Possible reasons for this are discussed below. When the normal and abnormal subgroups were compared (Table 5) little difference was found between the groups with respect to type II hyperlipoproteinaemia. There was a significantly higher prevalence $(P<0 \cdot 01)$ of type IV abnormality in the obese group. This was not present among subjects who had an abnormality other than obesity or cigarette smoking.

The overall prevalence of hyperlipoproteinaemia in an apparently healthy male group at work was therefore 15.3 per cent and was predominantly type IV abnormality.

\section{Discussion}

The frequency of hypercholesterolaemia and hypertriglyceridaemia in a community depends on an arbitrary choice of values for the upper limits of normal. At present, there is no widespread agreement as to what these limits should be. Indeed, both plasma cholesterol and triglyceride may represent graded risks at all levels, there being no clearcut separation into low risk and high risk groups (Fredrickson, 197I). Furthermore, studies of 'normal' populations have the disadvantage that many of the apparently normal individuals may have latent coronary atherosclerosis. At present, it is customary to choose upper fixed values for chol-

TABLE 5 Percentage prevalence of hyperlipoproteinaemia in normal subjects, those with an abnormality other than smoking or obesity, and those who are obese but otherwise normal

\begin{tabular}{|c|c|c|c|c|c|c|c|c|c|}
\hline \multirow[t]{2}{*}{ Age $(y r)$} & \multicolumn{3}{|c|}{ Normal } & \multicolumn{3}{|c|}{$\begin{array}{l}\text { Abnormality other than } \\
\text { smoking or obesity }\end{array}$} & \multicolumn{3}{|c|}{ Obesity as sole abnormality } \\
\hline & $I I$ & $I V$ & Total & $I I$ & $I V$ & Total & $I I$ & $I V$ & Total \\
\hline$<39$ & 3.8 & $8 \cdot 8$ & $12 \cdot 6$ & $3 \cdot 1$ & $6 \cdot 3$ & $9 \cdot 4$ & $6 \cdot 1$ & $22 \cdot 0 \star$ & $28 \cdot I^{\star}$ \\
\hline $40-44$ & 3.9 & I I $\cdot \mathbf{I}$ & $15{ }^{\circ} 0$ & $8 \cdot 2$ & 10.2 & 18.4 & $2 \cdot 5$ & $25 \cdot 2^{\star}$ & $27 \cdot 7^{\star}$ \\
\hline $45-49$ & $5 \cdot 7$ & $7 \cdot 2$ & $12 \cdot 9$ & $I \cdot 9$ & I I $\cdot \mathbf{I}$ & 13.0 & $5 \cdot 3$ & $17 \cdot 3^{\star}$ & $22 \cdot 6^{\star}$ \\
\hline $50-54$ & $I \cdot 2$ & 3.6 & $4 \cdot 8$ & $5 \cdot 6$ & $5 \cdot 6$ & $11 \cdot 2$ & $1 \cdot 8$ & $7 \cdot 0^{\star}$ & $8 \cdot 8^{\star}$ \\
\hline $55-59$ & $3 \cdot I$ & $3 \cdot 1$ & $6 \cdot 2$ & $2 \cdot 0$ & $8 \cdot 2$ & 10.2 & $\mathbf{I} \cdot \mathbf{I}$ & $15 \cdot 2^{\star}$ & $16 \cdot 3^{\star}$ \\
\hline
\end{tabular}

* $\mathrm{P}<0.01$ when compared to normal. 
esterol and triglyceride so that comparison of the prevalence of hyperlipidaemia can be made within a country and also between various countries.

The present study indicates a high prevalence of hypercholesterolaemia in the Glasgow conurbation whether the cut-off point is taken at 240 or $275 \mathrm{mg} / 100 \mathrm{ml}$. These cut-off points reveal prevalence rates of 38.3 per cent and 13.3 per cent, respectively. Oliver (I969) has reported a corresponding rate of 8 per cent using the cut-off point of $260 \mathrm{mg} / 100 \mathrm{ml}$ in a study of 2672 male subjects between 30 and 59 years in Edinburgh, while Veitch (1970), using manual methods, found that 21.4 per cent of male blood donors in the North of Scotland had a plasma cholesterol above $275 \mathrm{mg} /$ roo ml. In a Californian study, Wood et al. (1972), using similar cut-off points to those in the present investigation, found prevalence rates of 19 per centabove $240 \mathrm{mg} / 100 \mathrm{ml}$ and 4.5 per cent above $275 \mathrm{mg} / 100 \mathrm{ml}$. These various investigations are not directly comparable in that the Glasgow study consisted of men at work in manual, clerical, and professional occupational groups, while the North of Scotland study consisted of samples from volunteer blood donors. The Californian data were obtained from volunteers for a community health programme. None the less, the data may be useful in suggesting national and international trends.

Hypertriglyceridaemia also has a high prevalence in the West of Scotland. The cut-off points of 150 or $200 \mathrm{mg} / 100 \mathrm{ml}$ for upper limits for normal values reveal prevalence rates of 24 per cent and ro per cent, respectively. No comparable figures for other areas of Scotland or the United Kingdom have so far been published, but comparison with studies elsewhere suggests that plasma triglyceride values may be higher in California (Wood et al., 1972) and Stockholm (Carlson and Lindstedt, 1969).

Age-related plasma cholesterol and triglyceride values in subjects selected as normal on the basis of the same criteria in Glasgow as used in Stockholm show similar trends. The higher levels in California may be partly due to the fact that their subjects were non-fasting ( 2 slices of dry toast and fruit juice before venous sampling) and that obese subjects were not excluded from their normal group. Obesity has a considerable influence on the prevalence of hypertriglyceridaemia. Table 4 shows that the mean plasma triglyceride values for obese, but otherwise normal individuals, are 20 to $30 \mathrm{mg} /$ IOO $\mathrm{ml}$ higher than for non-obese, normal subjects. Obesity does not appear to affect plasma cholesterol levels. Comparison with other investigations is, therefore, difficult unless normal, non-obese subjects have been studied. The apparent increase in triglyceride levels in California as compared to
Glasgow and Stockholm can thus perhaps be related to the inclusion of obese subjects in their normal group.

The classification of hyperlipidaemia in terms of the hyperlipoproteinaemias has given a fresh stimulus to the study of the relation between plasma lipids and vascular disease. At present there is no general agreement as to the best method of classification, or what should be regarded as the upper limits of normal for the major plasma lipoprotein fractions (high density lipoprotein, low density lipoprotein, and very low density lipoprotein). Agreement as to classification and levels of normality are needed for consistency in determination of the prevalence of hyperlipoproteinaemias in the community and for comparison with results obtained elsewhere. In addition, there are major technical and methodological problems which contribute to the relative scarcity of published data regarding the prevalence of the hyperlipoproteinaemias. Various reports have, however, appeared. Thus, Wood et al. (1972) using age related upper normal limits for cholesterol and triglyceride reported overall prevalence rates in a 'normal' group (which did not exclude obese individuals) of 2.8 per cent for type II and 13 per cent for type IV hyperlipoproteinaemia. In the Glasgow group the overall prevalence rate of type II abnormality was 3.3 per cent, and I2 per cent for type IV abnormality. When, however, the normal group is considered separately, then the prevalence rates remain at around 3.I per cent for type II abnormality and fall to 7 per cent for type IV abnormality. The apparent decrease in the prevalence of the hyperlipoproteinaemias in the older age groups may well be related to the fact that the upper limits for normal cholesterol values reported by Fredrickson et al. (1967) for a group of American men are higher than those found in the West of Scotland. It is likely that the prevalence of plasma lipoprotein disorders in the community can be adequately studied only when normal values, based on quantitative measurements, are determined.

In assessing these results it should be emphasized that this is not a random sample of the general population, though it does represent an important economic group in the community. In addition, the use of total plasma cholesterol levels in the classification of type IIa hyperlipoproteinaemia may underestimate the prevalence of this abnormality. The measurement of low density lipoprotein cholesterol would be more accurate. Though quantitative lipoprotein typing is difficult and time consuming when large numbers of subjects are studied, it must be done before accurate prevalence rates can be determined. The results based on only semi- 
quantitative techniques underestimate the prevalence of lipoprotein abnormalities, especially type II, since an abnormally high low density lipoprotein cholesterol can be found in association with a normal total plasma cholesterol (Carlson and Lindstedt, 1969).

Thus in an area where there is a high incidence of coronary heart disease, there is also a high prevalence of lipoprotein abnormalities in apparently healthy men. Type IV is the commonest abnormality and is related in part to obesity. This does not occur with type II abnormality. These data suggest that dietary factors, such as total calorie or carbohydrate intake, may be important. A detailed community dietary survey is indicated to elucidate the contribution of diet to lipoprotein disorders in the West of Scotland area. Such a survey would also help to suggest what dietary factors might need to be controlled in the management of hyperlipoproteinaemia.

It must also be conceded that a high prevalence of hyperlipoproteinaemia in an area where there is a high incidence of coronary disease does not mean that they are causally related. Their clinical significance could best be determined by large scale, longterm prospective studies of 'at risk groups' or by demonstrating that the correction of lipoprotein abnormalities results in a reduction in the clinical manifestations of coronary heart disease in the community.

The study has been supported by funds made available by the Scottish Home and Health Department and the Renfrewshire King Edward Memorial Trust.

The organizers are indebted to the Managements, Trade Unions, professional associations, and employees of British Rail, British Steel Corporation, Caterpillar Tractor Co. Ltd., Civil Service, The Faculty of Procurators in Glasgow, I.C.I., Prestcold Scotland Ltd., and Weir-Pacific Valves Ltd., for their co-operation in arranging the surveys and participating in the examinations.

\section{References}

Annan, W., and Isherwood, D. M. (1969). An automated method for the direct determination of total serum cholesterol. Fournal of Medical Laboratory Technology, 26, 202.

Beaumont, J. L., Carlson, L. A., Cooper, G. R., Fejfar, Z., Fredrickson, D. S., and Strasser, T. (1970). Classification of hyperlipidaemias and hyperlipoproteinaemias. Bulletin of the World Health Organization, 43, 891.
Blackburn, H. (1970). The Pooling Project Report, Council on Epidemiology, American Heart Association. In Atherosclerosis. Proceedings of the Second International Symposium, p. 350. Ed. by R. J. Jones. Springer-Verlag, Berlin.

Burstein, M., Scholnick, H. R., and Morfin, R. (1970). Rapid method for the isolation of lipoproteins from human serum by precipitation with polyanions. Fournal of Lipid Research, 11, 583.

Carlson, L. A., and Böttiger, L. E. (1972). Ischaemic heart disease in relation to fasting values of plasma triglycerides and cholesterol. Lancet, 1, 865.

Carlson, L. A., and Lindstedt, S. (1969). The Stockholm Prospective Study. The initial values for plasma lipids. Acta Medica Scandinavica, 185, Suppl. 493.

Fredrickson, D. S. (197I). Mutants, hyperlipoproteinaemia and coronary artery disease. British Medical fournal, $2,187$.

Fredrickson, D. S., Levy, R. I., and Lees, R. S. (1967). Fat transport in lipoproteins - An integrated approach to mechanisms and disorders. New England fournal of Medicine, 276, 34, 94, 148, 215, and 273.

Hawthorne, V. M., Gillis, C. R., and MacLean, D. S. (1972). Monitoring health in Scotland. International fournal of Epidemiology, 1, 369.

Kannel, W. B., Dawber, T. F., Friedman, G. D., Glennon, W. E., and McNamara, P. M. (1964). Risk factors in coronary heart disease; an evaluation of several serum lipids as predictors of coronary heart disease. The Framingham Study. Annals of Internal Medicine, 6r, 888.

Kessler, G., and Lederer, H. (1966). Fluorometric measurement of triglycerides. In Automation in Analytical Chemistry, Technicon Symposia 1965, p. 341. Ed. by L. T. Skeggs. Mediad Inc., New York.

Lees, R. S., and Hatch, F. T. (1963). Sharper separation of lipoprotein species by paper electrophoresis in albumincontaining buffer. Fournal of Laboratory and Clinical Medicine, 61, 518.

M.R.C. Committee on the Aetiology of Chronic Bronchitis (1965). Definition and classification of chronic bronchitis. Lancet, $1,775$.

Oliver, M. F. (1969). Problems in the presymptomatic diagnosis of ischaemic heart disease. In Modern Trends in Cardiology, p. 50. Ed. by A. Morgan Jones. Butterworths, London.

Registrar General for Scotland (1972). Annual Report for 1971, Part I, No. I 7. H.M.S.O., Edinburgh.

Rose, G. A., and Blackburn, H. (1968a). Cardiovascular survey methods. World Health Organization. Monograph Series, No. 56, p. 172. W.H.O., Geneva.

Rose, G. A., and Blackburn, H. (1968b). Cardiovascular survey methods. World Health Organization. Monograph Series, No. 56, p. 91. W.H.O., Geneva.

Veitch, A. G. (1970). A survey of serum cholesterol levels in apparently healthy individuals in the North of Scotland. Health Bulletin (Edinburgh), 28, 56.

Wood, P. D. S., Stern, M. P., Silvers, A., Reaven, G. M., and Groeben, J. Von der (1972). Prevalence of plasma lipoprotein abnormalities in a free-living population of the Central Valley, California. Circulation, 45, ir4.

Requests for reprints to Dr. A. R. Lorimer, Cardiology Department, Royal Infirmary, Glasgow $\mathrm{G}_{4}$ OSF. 